\title{
La encuadernación del impreso antiguo en México: reflexiones sobre un problema de conoci- miento patrimonial
}

\author{
Alberto Compiani * \\ Idalia García ** \\ Thalía Velasco ***
}

Artículo recibido:

14 de diciembre de 2004.

Artículo aceptado:

4 de mayo de 2005.

\section{RESUMEN}

La encuadernación es uno de los elementos históricos distintivos que favorecen la valoración cultural del libro antiguo como objeto patrimonial. El análisis de la encuadernación como un problema de conocimiento es una tarea pendiente en el terreno histórico mexicano. Ciertamente existen trabajos anteriores que muestran su valor cultural, pero son iniciativas inconclusas que han posibilitando la destrucción de numerosas encuadernaciones históricas por lo cual el mensaje del pasado queda mutilado. Este trabajo analiza las tendencias del estudio de la encuadernación en México y define su importancia como elemento patrimonial.

* Escuela Nacional de Conservación y Restauración, México. acompiani@yahoo.com

** Centro Universitario de Investigaciones Bibliotecológicas de la UNAM, México. pulga@cuib.unam.mx

*** Instituto Nacional de Antropología e Historia, México. thaliavelasco@hotmail.com

INVESTIGACIÓN BIBLIOTECOLÓGICA, Vol. 20, Núm. 40, enero/junio, 2006, México, ISSN: 0187-358X. pp. 53-72 
Palabras Clave: Encuadernación histórica; Libros antiguos, Patrimonio cultural en México.

\section{ABSTRACT}

Bookbinding of antique prints in Mexico: reflections on a problem of knowledge in cultural heritage Alberto-Compiani; Idalia-García and Thalía-Velasco

Bookbinding is one of the distinctive historical elements which support cultural value of rare books as patrimonial objects. Analysis of bookbinding as a knowledge problem is a pending task in Mexican history, although there certainly are previous papers which show its cultural value. However those incomplete initiatives have allowed the destruction of many important bookbindings, a fact equivalent with the mutilation of the message from the past. Today's tendencies on bookbinding study in Mexico are analyzed and its importance as a patrimonial element is defined.

Keywords Historical bookbinding; Rare books; Cultural heritage in Mexico.

$\infty$

"No existe cosa más bella ni que haya prestado más beneficios a la Humanidad que el libro bueno; además, no bay nada que embellezca tanto como ellos el interior de una casa; el buen libro es gracia, decoro y luz, aun en el hogar modesto. Por el culto que se da al libro se hacen grandes los pueblos".

Mariano Monje Ayala (1995)

\section{INTRODUCCIÓN}

E n los últimos tiempos prácticamente todos los aspectos del patrimonio cultural de los países se analizan desde múltiples perspectivas, con objeto de preservar mejor el pasado heredado. Estas revisiones han puesto de manifiesto varios problemas de conocimiento relacionados con los bienes patrimoniales y la necesidad de ahondar en las problemáticas que la misma falta de conocimiento genera para hacer una conservación adecuada del recurso cultural a largo plazo. Con ello se ha evidenciado la necesidad de favorecer el trabajo multidisciplinario para recuperar el conocimiento construido con 
anterioridad, y así definir claramente problemas de investigación que puedan aportar soluciones ideales para garantizar la salvaguarda de bienes patrimoniales de cualquier naturaleza a largo plazo.

Desde esta perspectiva el conjunto patrimonial compuesto por los impresos antiguos ha sido objeto de numerosas investigaciones tendientes a distinguir su valor y significado, y éstas han resaltado la problemática de conservación de esos materiales. La intención de estos trabajos busca también favorecer la socialización de la riqueza cultural y difundir las características mismas por las cuales se valora patrimonialmente. Todo trabajo de salvaguarda de bienes patrimoniales tiene un sentido social porque asegura la transmisión de valores culturales y sociales de los que son depositarios.

Sin embargo en México, a pesar de estas tendencias internacionales, el conocimiento de este conjunto librario no se realiza paralelamente al de otros bienes de naturaleza cultural. Por eso en este caso no es arriesgado afirmar que la falta de conocimiento del objeto patrimonial abre una permanente situación de riesgo de pérdida definitiva. Es decir, en tanto que no sepamos qué tipo de objetos heredamos, cuántos son éstos, y cuáles son las características por las que adquieren valor, no estaremos en posibilidad de protegerlos, y menos aún de transmitirlos a las generaciones siguientes.

Estos aspectos son factores importantes que dificultan la tarea primordial de la protección patrimonial que comienza con el registro de los objetos custodiados. Reconocer y salvaguardar los bienes bibliográficos como nuestra herencia cultural implica comprender muy bien su evidencia material y el significado que ésta adquiere en la construcción moderna de nuestra visión patrimonial. Esta visión reconoce que un bien cultural no puede ser realmente comprendido si no se recupera al mismo tiempo el entorno que lo contextualiza. En el libro, ese entorno es la encuadernación que lo vincula con su función básica: un texto escrito para ser leído.

\section{VALORACIÓN CULTURAL DE LA ENCUADERNACIÓN}

En el reconocimiento del valor de la cultura el libro siempre ha tenido un papel preponderante como elemento de transmisión de conocimiento entre generaciones y por tanto su eficacia es incuestionable en la construcción de la memoria humana. Se trata sin duda de un ingenio que desde su origen fue diseñado tan eficientemente que ha sufrido muy pocas modificaciones por lo que su permanencia está garantizada por mucho tiempo.

Esta relevancia cultural permite que en la actualidad numerosas bibliotecas compuestas en gran parte por impresos antiguos, salgan a la luz pública a 
través de exposiciones (presenciales y virtuales), artículos de revistas (de divulgación y especializadas) y estudios especializados, además de que la tecnología moderna permite acceder al texto completo de un impreso antiguo que ha sido digitalizado.

Efectivamente, el impreso antiguo constituye una riqueza patrimonial de carácter excepcional y requiere ser presentado tal y como fue producido. De ahí que los proyectos digitales sean reproducciones facsimilares y no meramente una sustitución del texto original por medios automatizados. Ese texto original tan altamente valorado se presenta tal y como fue compuesto originalmente, con su caja tipográfica, líneas, signaturas, reclamos, ortografía y gramática, así como cada una de las partes que lo caracterizan y definen.

Estas partes que, no debemos olvidar mencionar, constituyen un entramado social, económico, político y cultural resultado de un proceso de producción manual. Así, la portada, los preliminares, el texto de la obra, los índices y tablas, y las ilustraciones que acompañan la caja tipográfica responden a un tiempo y situación específicos que conocemos en la medida en que nos acercamos al mundo cultural del que son resultado.

El proceso de producción de un impreso antiguo ejemplifica claramente cómo un bien intangible se materializa a través de distintos elementos físicos y se convierte en un bien tangible. Este procedimiento que convierte al pensamiento o sentimiento de un ser humano en un objeto material, implica distintas etapas que es necesario conocer para poder realizar un proceso de valoración cultural.

Aquí nos interesa acercarnos al momento en que ha terminado el proceso de impresión y se han cubierto todos los requerimientos legales que imperaban en la época de producción del impreso antiguo. Es necesario precisar que nos interesa resaltar todo producto al que ha dado lugar la imprenta de tipos móviles; es decir habremos de distinguir la encuadernación histórica que poseen tanto los incunables (producidos entre 1455 y 1500) como los libros antiguos (producidos entre 1500 y 1800). ${ }^{1}$

En esos años el impreso antiguo podía circular socialmente si previamente se habían cosido los cuadernillos que lo integraban o éstos se encuadernaban con una simple cubierta de pergamino que se realizaba por cuenta del impresor. Este proceso abría un ciclo particular en la historia de cada impreso antiguo, que nos ha dejado unos libros "marcados con los estigmas de los usos de que habían sido objeto durante siglos". 2

1 Cabe recordar que esta separación terminológica está determinada por las diferencias de tratamiento documental, tanto bibliográfico como catalográfico que requiere cada uno de estos objetos para proporcionarnos información útil.

2 Henri-Jean Martín, Historia y poder de lo escrito, Gijón: Trea, 1999. p. 11 
Es en este momento cuando el encuadernador participaba y se hacía cargo del resto de la producción del libro. Aquí el mensaje impreso era dotado de una cubierta que, además de proporcionarle una protección diseñada expresamente para ser manejada por las manos del hombre, lo conservaba y protegía del contexto al cual pertenecía. Esta cubierta será determinante para la conservación futura del impreso antiguo. Algunos impresos tendrán una encuadernación simple y económica acorde con el uso que recibiría, y otros se transformarán en verdaderas obras de arte, lo que dependerá del gusto de su poseedor.

Por esa razón el libro sólo puede denominarse como tal hasta el momento en el que la encuadernación está acabada y el libro está listo para ser ofrecido y posteriormente consultado por un lector. ${ }^{3}$ Por ello los ejemplares de una misma edición (mismo impresor y fecha de edición) cuentan con características constructivas y de decoración diferentes. Esta parte de la materialidad le otorga una historia particular a cada impreso y en ocasiones los puede convertir en ejemplares únicos, y por tanto revestirlos de un valor excepcional e irrepetible. Por eso, la encuadernación, lejos de ser un elemento "accesorio" del libro, es parte intrínseca del mismo.

En el siglo XVI se inicia una era verdaderamente brillante para la encuadernación, favorecida por la multiplicación de libros que van apareciendo como consecuencia inmediata del progreso tipográfico, cuyas viñetas ofrecieron un precioso elemento para la decoración exterior de los libros [...] La encuadernación adquiere definitivamente la categoría de obra artística. Para ello prestaron su concurso y atención los espíritus más elevados y los artistas más eminentes. ${ }^{4}$

No es extraño que este desarrollo artístico se presente de forma paralela en el siglo XVIII con el nacimiento de la bibliofilia, una pasión que conduce a valorar el libro antiguo, ya sea por su antigüedad, por la belleza de su soporte o incluso por el arte de su envoltura. Esta primera valoración también coincide con la concepción de las bibliotecas como instituciones conservadoras de colecciones históricas, gracias a lo cual comienzan a separarse estos

3 De acuerdo con algunos investigadores, como Manuel J. Pedraza, el libro se puede denominar como tal en el momento en el que está cosido, por lo que la encuadernación sería una parte externa del libro. De hecho, para este investigador, una encuadernación puede ser sustituida en el momento en el cual ésta está deteriorada. Dicha posición se contrapone a la visión del libro como un objeto integral, en la cual cada una de sus partes forma parte sustancial del conjunto. Este punto deberá de ser discutido a profundidad, sin embargo al no ser el objetivo del presente artículo sólo se cita la importancia de su discusión. Cfr. Manuel J. Pedraza Gracia, "Concepto, estructura material y formal y descripción del libro antiguo”, en Tasación, valoración y comercio del libro antiguo: Textos y materiales, Zaragoza: Universidad, 2002. p. 11-48.

4 Emilio Brugalla, Tres ensayos sobre el arte de la encuadernación, Madrid: Ollero \& Ramos, 2000. p. 27. 
impresos antiguos de los de uso común para garantizar la integridad de su forma original. ${ }^{5}$

En este contexto histórico comenzarán a desarrollarse los primeros tratados de organización bibliotecaria y la apreciación del impreso antiguo sentará todo un precedente para el trabajo posterior de los bibliógrafos en el siglo XIX. Pero este trabajo intelectual que da origen a las técnicas bibliográficas de descripción de impresos antiguos, le otorgó preferencia al valor textual de ellos y relegó a un aspecto secundario los valores históricos.

Cabría recordar que el pensamiento histórico del siglo XIX, también permitió que el impreso antiguo comenzara a reconocerse como un bien patrimonial digno de la atención del coleccionismo particular. Dicho reconocimiento hizo posible la consolidación de colecciones importantes, pero también representó el desarraigo de numerosos materiales que fueron removidos y saqueados de los sitios en donde habían sido conservados durante siglos.

Es en parte por lo anterior como surge el interés por el estudio y la clasificación de los impresos antiguos, gracias a lo cual contamos hoy con valiosos repertorios bibliográficos sin cuya ayuda no podríamos identificar puntualmente los libros que hoy conservamos. Pero como hemos dicho, tal estudio se limitó al valor textual del libro, es decir a aquello que fue impreso, consideración que, salvo excepciones, no distinguió a los demás elementos que le dan historicidad al impreso antiguo, en especial, la encuadernación.

El conjunto de elementos históricos que constituyen también a estos impresos cobra importancia hasta la segunda mitad del siglo XX, cuando se establece el interés por conocer al libro en el contexto cultural en el que lo heredamos. De esta manera cobra relevancia patrimonial el ejemplar de un impreso antiguo sobre la edición conservada. Esta apreciación, soportada principalmente por la codicología permite que el libro comience a valorarse no sólo por la información que contiene sino también por la estructura que lo compone y los elementos que narran su devenir histórico.

El libro ya no es sólo contenido, sino continente. Se reconoce como un objeto en donde el funcionamiento armonioso de los elementos que lo componen garantiza su función como guardián de la memoria, pero, a su vez, como forma material, atestigua el tiempo y el espacio que le dio origen. No obstante, la materialidad del objeto y la realidad de su producción nos obligan a desdibujar el idealismo romántico con el que nos acercamos frecuentemente a cualquier historia del libro: durante la época de la producción de impresos antiguos, los lectores siempre fueron una minoría y no un fenómeno multitudinario.

5 Cfr. Amalia Sarrá Rueda, "De libros raros y antiguos", en La estética del libro español: manuscritos e impresos españoles hasta finales del siglo XVI en la Biblioteca Lázaro Galdiano / José Antonio Yeves Andrés, Madrid: Fundación Lázaro Galdiano, 1997. p. 71-72. 
Este mero hecho determinó que las bibliotecas fueran un espacio privilegiado de conocimiento y valoración en el que se encontraban también evidencias de la encuadernación.

Como se dan casos hoy en día, muchos bibliófilos estaban tan interesados (o aún más) en hermosas encuadernaciones, elegante tipografía, grabados xilográficos intercalados o incorporados al texto (desde los primeros incunables), como en el contenido del libro mismo. Ser dueño de libros preciosos era también una manera de presumir opulencia y gusto principesco. ${ }^{6}$

Si bien el desarrollo de este conocimiento nos mostró que algunas de las encuadernaciones más apreciadas tuvieron su origen en los talleres de imprenta más notables como el del Manuzio en Italia, también salieron a la luz otros estilos de encuadernación de gran maestría que hoy siguen siendo la obra de artistas anónimos, algo tan fundamental que de esto ha dependido en gran parte la conservación de los impresos antiguos.

La mirada historiográfica sobre el desarrollo del conocimiento nos permite comprender ahora que la valoración de impresos antiguos es

un proceso en el que mediante un examen minucioso, desde diversas perspectivas y con muy diferentes saberes, descubrimos los rasgos de una pieza o de un conjunto de piezas que nos permiten concretar su valor cultural. ${ }^{7}$

El reconocimiento y concreción de dicho valor es el resultado del estudio entre la relación directa y vinculante que existe entre un libro, la encuadernación que lo abriga y todos aquellos elementos que nos permiten comprender al objeto en los diferentes mundos sociales por los que ha pasado desde el momento de su producción hasta el momento de su actual conservación. Pero a pesar de la relevancia cultural que hemos depositado en el impreso antiguo todavía falta que el conjunto de valores que le reconocemos forme parte de una comprensión puntal y compartida como bien cultural.

6 Jacques Lafaye, Albores de la imprenta: el libro en España y Portugal y sus posesiones de ultramar, siglos XV y XVI, México: FCE, 2002 p. 66

7 Julián Martín Abad, "La valoración del libro: el punto de vista del bibliotecario de fondo antiguo", en Ciclo de conferencias sobre bibliofilia y mercado del libro, Biblioteca Histórica Marques de Valdecilla. Texto disponible en:

http://www.ucm.es/BUCM/foa/conferencia2.pdf [Consultado: noviembre de 2004] p. 4 


\section{LAS ENCUADERNACIONES HISTÓRICAS DENTRO DEL UNIVERSO DE LOS BIENES CULTURALES}

El proceso de consolidación del impreso antiguo como bien cultural ha tenido diversos desarrollos en los diferentes países y no ha logrado imponerse una visión compartida de la construcción de su valor entre las disciplinas que comparten este objeto de estudio. Ciertamente reconocemos que para funcionar adecuadamente como elemento de transmisión cultural el libro antiguo requiere del desempeño armónico de todas sus partes. Se trata de un objeto constituido básicamente por un soporte, ya sea papel o pergamino, que forma los cuadernillos sujetos a través de una costura que los mantiene unidos y que permite una adecuada apertura. Sin el funcionamiento adecuado de estos elementos, el libro no puede cumplir con las funciones a las que fue destinado o éstas se ven limitadas.

La encuadernación como objeto de interés ha estado presente desde el siglo XIX, pero ésta se enfocó mayoritariamente a distinguir los tipos de encuadernaciones históricas que se habían conservado. En esta tendencia sobresale el trabajo realizado por los bibliógrafos y bibliotecarios ingleses, franceses y alemanes. Gracias a este interés contamos para la investigación con numerosos catálogos e inventarios de época que identifican los tipos de encuadernación de impresos antiguos.

No será sino hasta el siglo XX cuando se dará una revalorización cultural de la encuadernación vinculada directamente al impreso que resguarda. Podemos identificar entre los trabajos más notables con esta orientación el de Ernst Philip Goldschmidt (Gothic and Renaissance Bookbindings), ${ }^{8}$ quien por primera vez va a puntualizar un conocimiento sobre la encuadernación con elementos académicos más que meramente descriptivos, como lo hacían los textos publicados desde finales del siglo XIX. Su investigación se suma al esfuerzo realizado por los primeros estudiosos de la bibliografía material, ${ }^{9}$ en el estudio del impreso antiguo como objeto cultural producto de un tiempo específico.

A partir de ese momento la encuadernación comenzó a concebirse como elemento patrimonial, y con ello se inició la recuperación de las técnicas de encuadernación tradicionales, lo cual se vio reflejado en la elaboración de manuales y en la reimpresión de textos antiguos en donde este elemento histórico desempeñaba un papel. Efectivamente no existía en ese entonces una concepción patrimonial como la que actualmente tenemos, pero ya empezaba a

8 Edición publicada por primera vez en 1928.

9 Mirjam Foot, "The future of bookbinding research", en The book encompassed: studies in twentieth-century bibliography / ed. Peter Davison, Cambridge: Cambridge University Press, 1992. p. 99. 
establecerse la necesidad de respetar la "originalidad" del conjunto librario, así como la importancia de la encuadernación como elemento significativo de la historia del impreso.

Ciertamente esta tendencia siguió favoreciendo la distinción de los estilos de encuadernación más que los procesos de manufactura, y con ello la caracterización material de las cubiertas. Pero sin duda favoreció el desarrollo de otras investigaciones que pusieron el énfasis en el estudio de los materiales de las encuadernaciones históricas; con lo cual se establecieron importantes bases para hacer de la encuadernación una parte fundamental de la salvaguardia del patrimonio librario.

Los trabajos realizados en Inglaterra, Francia, Alemania y Estados Unidos, que son resultado de este proceso, han permitido hacer planteamientos metodológicos sobre el estudio de la encuadernación, pero especialmente aplicar a ella elementos de la teoría de la restauración para conservar el impreso antiguo. Y también han facilitado la elaboración de interesantes estudios que resaltan las técnicas de encuadernación en ciertos momentos históricos y la confección de censos completos sobre estilos de encuadernación que distinguieron a ciertas épocas históricas.

El reconocimiento del valor del impreso antiguo como bien cultural heredado de generaciones pasadas, también se vio favorecido con el desarrollo de la bibliografía material y sus aportaciones metodológicas. De esta forma las descripciones como formas de representación de objetos materiales han ido gradualmente evolucionando y son ahora cada vez más precisas, detalladas y completas, al grado que se han alcanzado acuerdos internacionales que se manifiestan en la elaboración de normas internacionales. Pero en éstas sigue prevaleciendo el valor textual sobre los elementos históricos, como las anotaciones manuscritas, los ex libris y también las encuadernaciones. Elementos, estos últimos, que pese a su importancia han sido descritos escasamente y sin normalización.

Como resultado de lo anterior, tales elementos son considerados discrecionalmente por la biblioteca que cataloga sus impresos antiguos sin considerar la relevancia que éstos tienen para ubicar y relacionar un libro con quienes lo han poseído. Así, las descripciones bibliográficas que consideran la importancia de informar sobre la procedencia de un impreso antiguo, en su mayoría obvian la indicación del elemento histórico mediante el cual se ha llegado a esa conclusión.

Por otra parte el conocimiento histórico que puso su interés en la historia del libro contribuyó notablemente a identificar los aspectos relevantes que el impreso antiguo tiene como objeto material en el mundo social y cultural en el que se inserta. Con ello se pudo reconocer el trabajo que realizaba con 
cierta autonomía el gremio de impresores y encuadernadores que nos ha dejado su legado.

Es indudable que la investigación desarrollada durante más de un siglo sobre el mundo de la encuadernación ha contribuido notablemente a consolidar su valor cultural, tanto de forma aislada como integrada al objeto funcional. Pero también resulta notorio que este desarrollo del conocimiento no haya logrado consolidar su papel en el estudio de la procedencia de las colecciones.

La procedencia es un tema de investigación que fortalece el valor cultural del impreso antiguo y que permite comprender cómo esas magníficas bibliotecas del pasado se han ido congregando en muchas colecciones modernas. Una historia que desgraciadamente ha sido victima de numerosos procesos de reencuadernación que no solamente han eliminado las encuadernaciones históricas originales sino que también han afectado considerablemente al texto impreso, tan apreciado.

La comprensión moderna del bien cultural en lo que respecta a la encuadernación histórica, tampoco ha logrado conciliar los intereses de investigación de las disciplinas que tienen la responsabilidad de garantizar la permanencia del objeto original para las generaciones futuras. De ahí que en la valoración cultural de la encuadernación sobresalga la apreciación de la institución de custodia más que la del elemento material. Esta afirmación puede observarse por ejemplo en la elaboración de catálogos especializados como el de la British Library, ${ }^{10}$ un instrumento electrónico que permite apreciar una imagen digital de calidad con posibilidad de ampliarla a pantalla completa, lo que permite apreciar los detalles de cada encuadernación registrada.

Este tipo de instrumentos, de gran utilidad para la investigación, no suelen relacionarse siempre con otros semejantes para desarrollar una visión completa del problema patrimonial que representa el impreso antiguo. Sabemos que para determinar el valor cultural de un impreso antiguo siempre deben establecerse dos puntos: los aspectos textuales resultado de su impresión y los aspectos históricos resultados de su posesión.

Así como hemos llegado a un acuerdo sobre la descripción del valor textual, debemos caminar ahora hacia un concierto en la definición e identificación de los elementos históricos para que un impreso antiguo sea reconocido como un bien cultural y así sea transmitido históricamente. Esto implicaría fortalecer en la formación de los conservadores y restauradores de encuadernaciones el conocimiento del objeto y sus relaciones culturales como paso previo a su labor.

Quizá de esta manera la identificación de una encuadernación histórica, tanto en estilo como en material, pueda ser registrada de manera homogénea

10 Información disponible en http://www.bl.uk/catalogues/bookbindings/welcome.htm [Consultado: marzo de 2005] 
y contribuir así al estudio fiable de su manufactura y también a aceptar su relevancia en el conocimiento del impreso antiguo. No hay que olvidar que la valoración cultural de la encuadernación ha sido el soporte de identificación de verdaderos estilos como el Mudéjar, el Escurialense o el Grolier.

Este tipo de estudios y otros más específicos que han distinguido y caracterizado a cada estilo de encuadernación, permiten que otras instituciones de custodia puedan aportar mayores elementos para valorar culturalmente un objeto bibliográfico. Efectivamente,

[...] cada ejemplar concreto es siempre un producto histórico. Quiere esto simplemente decir que el paso del tiempo habrá adherido a cada ejemplar de la edición elementos foráneos (que se han convertido en propios y caracterizadores de ese ejemplar concreto), relatándonos nombres de sucesivos poseedores y en ocasiones añadiendo además signos específicos de posesión [...] La consideración de cada ejemplar como producto histórico admite la posibilidad de considerarlo, al subrayar determinados detalles, como producto bibliotecario y como producto bibliofílico. Son las historias mil que permiten añadir a su noticia los calificativos de único, raro, curioso, esencial para determinada investigación, etc. ${ }^{11}$

Es con esta consideración como debemos comprender que el valor de los impresos antiguos conservados no está únicamente relacionado con aquellos que fueron producidos ahí donde la institución bibliotecaria custodia. Más bien la composición de una colección moderna en términos patrimoniales es el resultado de intercambios culturales que podemos conocer y documentar si le damos importancia a todos los elementos que tiene un bien bibliográfico.

Un bien que pese a toda la relevancia cultural que podamos otorgarle es también un mero producto de mercado. Pero hablamos de un producto que se transformó en un verdadero negocio que sirvió a fines tan cruciales como la difusión del conocimiento. En efecto, sobre el impreso antiguo y sus funciones se ha construido una memoria colectiva que no debemos olvidar.

\section{INVESTIGACIÓN MEXICANA SOBRE LA ENCUADERNACIÓN HISTÓRICA}

La primera mirada de cualquier persona en un fondo antiguo, está dedicada a las encuadernaciones. Esta mirada es inevitable, pues a diferencia de otros

11 Julián Martín Abad, "Incunables, post-incunables y libros antiguos”, en Exposición virtual Civitas Librorum (La ciudad de los libros), Centro Virtual Cisneros, Universidad de Alcalá. Texto disponible en

http://www.centrocisneros.uah.es/civitas/texto4.htm [Consultado: marzo de 2005] 
tiempos solemos acomodar los libros en los estantes por los lomos, en los cuales encontramos la primera referencia al título de la obra en cuestión, por lo que las encuadernaciones son las cartas de presentación de cualquier libro, sea antiguo o moderno.

Naturalmente los impresos antiguos que actualmente se conservan en bibliotecas mexicanas no solamente fueron producidos en el territorio de la colonia novohispana; por el contrario, existen en nuestras colecciones ediciones europeas que ilustran intercambios culturales de gran complejidad y riqueza. En estos objetos encontramos la representación de un mundo cultural que hemos heredado de otras generaciones, pero que no valoramos en la misma medida y relevancia, cosa que sí hacen en otros países.

Dicha situación lamentablemente refiere, en primer lugar, al problema del registro e inventario de las colecciones de impresos antiguos que existen a lo largo y ancho del territorio mexicano. Pero en segundo lugar, hablamos de la realidad institucional relacionada con la custodia, lo cual nos conduce a reflexionar sobre el escaso valor social que tienen en México tanto el libro como la biblioteca, y en el hecho de que no logramos colocar en las preocupaciones culturales la específica problemática patrimonial del impreso antiguo.

Pese a la existencia de la encuadernación como objeto de estudio en otras latitudes, en nuestro país este elemento cultural ha estado relegado en la valoración y en la investigación especializada a un segundo -o tercer- plano, pues lejos de concebirla como parte del bien cultural, se le reconoce un valor meramente funcional, lo cual deja de lado la información que la encuadernación como elemento histórico le proporciona al impreso antiguo al reconocerlo como objeto patrimonial. De lo anterior podría desprenderse la importancia misma que la sociedad mexicana le ha dado tradicionalmente al contenido del libro, lo que ha provocado que se estudie y conserve el libro como objeto, priorizando el texto o mensaje depositado en los impresos, más que los elementos que constituyen parte de su materialidad, como la ilustración o la encuadernación.

La misma apreciación también ha producido que los escasos estudios dedicados al impreso antiguo olviden resaltar los elementos históricos sobre los que se soporta el valor cultural que se les reconoce a tales impresos. En todos estos textos, la encuadernación es completamente ignorada o apenas breve y superficialmente mencionada. De ahí que la bibliografía existente para darle soporte a la investigación sea escasa y pobre en comparación con la bibliografía procedente de otras tradiciones.

Este panorama se refleja claramente en la importancia que las bibliotecas y archivos mexicanos le dan al tema. Aunque es escasa la realización de inventarios, registros y catálogos, en éstos la descripción de las encuadernaciones 
es mínima y en muchas ocasiones se omite por completo. Se olvida así que el tipo de materiales y su cubierta, así como el estado de conservación de los volúmenes representa una valiosa información histórica para reconocerlos como bienes culturales.

En México la encuadernación no ha cobrado relevancia a pesar de que en los últimos tiempos el impreso antiguo sí ha alcanzado el estatus de objeto de estudio. En parte esta situación se mantiene por el tipo de valoración que existe dentro del propio gremio de los conservadores y bibliotecarios en relación con la encuadernación histórica.

Pese a su innegable importancia testimonial, en nuestro país no se le presta la debida atención a las encuadernaciones como objeto de estudio. Efectivamente, se sabe muy poco sobre el tipo y el material de las encuadernaciones que tienen los impresos antiguos conservados en las bibliotecas mexicanas, y sobre las modas y las tendencias que podrían caracterizar a toda una época histórica.

Con esta pobre perspectiva el libro es únicamente concebido como un mensaje escrito, y se deja de lado la información que puede aportar éste como "objeto arqueológico". Una somera revisión de las revistas y libros especializados nos mostrará el nivel de importancia que se le ha dado al estudio de la encuadernación en diversas escuelas de pensamiento.

El trabajo de Romero de Terreros (1932) sobre las encuadernaciones mexicanas, pone ciertamente más énfasis en el valor de la encuadernación, que en los libros que portan dignamente. Pese a ello, este trabajo resulta actualmente el texto inevitable de referencia para quién desea estudiar la encuadernación de los impresos antiguos, pues a pesar de los años es un trabajo cuya riqueza y detalle se extraña en el marco de nuestra literatura contemporánea especializada.

Efectivamente, carecemos de una bibliografía nacional que sea el resultado de un trabajo consolidado y continuo sobre el conocimiento del impreso antiguo. Es importante señalar que esto se debe al escaso interés que tienen en México para nosotros, tanto la historia del libro como la de la biblioteca. Simplemente no existe una tradición académica sobre el estudio de los materiales y las técnicas de manufactura del impreso, ni tampoco sobre los aspectos relacionados con la naturaleza social y cultural de este tipo de objetos.

Si bien en el extranjero el conocimiento sobre este objeto cultural y sus relaciones históricas ha sido ampliamente difundido y discutido, en nuestro país la situación apenas empieza a modificarse. Como bien lo señala Sánchez Bueno, ${ }^{12}$ siendo México un país propenso a la realización de estudios arqueológicos, se ha ignorado casi por completo el estudio de materiales como

12 Cfr. María Cristina Sánchez Bueno de Bonfil, El papel del papel en la Nueva España, México: INAH, 1993. 
el papel. Es decir, aunque se realizan innumerables investigaciones de los objetos arqueológicos como fuentes documentales, este tipo de estudios no se realiza para los bienes bibliográficos.

Los investigadores mexicanos han preferido el texto escrito, y dejado de lado este otro tipo de información que se encuentra también contenida en el objeto material, que como ya hemos mencionado se propone identificar puntualmente los elementos históricos que testimonian el devenir del impreso desde su confección hasta su conservación en las bibliotecas.

El principal problema que encontramos en nuestro país para investigar el impreso antiguo como objeto utilizado en algún momento de la historia, está relacionado con el registro patrimonial del mismo. Por esto resulta lamentable que pese a la existencia de una notable tradición bibliográfica mexicana no se haya todavía definido un modelo general de registro que cuando menos resalte todos los elementos que distinguen culturalmente a un impreso antiguo.

Efectivamente, esta distinción reconoce no sólo las características de impresión del objeto sino también otros aspectos que le dan historicidad. "El uso del libro se manifiesta en su evidencia histórica y mediante ésta podemos acercarnos a la comprensión del libro en su medio social". ${ }^{13}$ Por tanto los elementos históricos requieren ser representados en los modelos bibliográficos para garantizar así su conocimiento y posterior valoración.

En los trabajos mexicanos de registro e inventario realizados sobre colecciones de impresos antiguos todavía no se contempla como elemento esencial la relevancia de informar sobre los elementos históricos que posee el objeto que se describe. Es decir, no les hemos dado la relevancia que merecen las marcas de fuego, las anotaciones manuscritas y las encuadernaciones que caracterizan a esos impresos.

Esta falta de registro del tipo de encuadernación en un impreso antiguo también ha propiciado su escasa valoración dentro del patrimonio cultural y por tanto el desinterés como tema de investigación. Ni siquiera trabajos tan importantes como los de García Icazbalceta o Toribio Medina incluyen información sobre el tipo de encuadernación que poseían los impresos que describieron.

Esto afecta necesariamente la comprensión e identificación de las encuadernaciones conservadas en las colecciones bibliográficas, pues también determina las condiciones de conservación de las encuadernaciones, lo que se debería soportar sobre una valoración cultural previamente construida y fundamentada por el desarrollo de un conocimiento especializado. Así sin la inclusión de la encuadernación en la descripción de un impreso antiguo, ésta

13 Idalia García, "El legado bibliográfico en México: un aspecto inconcluso de la investigación bibliotecológica”, en Memoria del XXI Coloquio de Investigación Bibliotecológica y de la Información: la investigación bibliotecológica en la era de la información, México: UNAM. CUIB, 2004. p. 244. 
puede ser modificada sin que el hecho se considere relevante. Y lo mismo ocurre cuando el conservador o restaurador tiene que realizar una actuación sobre el impreso sin tener información que lo ayude a tomar decisiones relacionadas con el valor cultural del objeto material.

Es indudable que poseemos ricos acervos bibliográficos en los que existen impresos antiguos que tienen encuadernaciones dignas de estudio, pero la falta de reconocimiento de su valor como bienes culturales ha negligido e incluso mantenido en el olvido este tipo de información histórica. A diferencia de lo realizado en otras latitudes, no tenemos certeza respecto a la situación propia de la Nueva España debido a la falta de estudios específicos en esta materia. Oficialmente no existía el gremio de encuadernadores, y por ello no se puede asegurar si era usual que éstos trabajaran dentro de las imprentas novohispanas. Probablemente existieron algunos encuadernadores que por gozar de cierto prestigio pudieron asentarse y constituirse como empresas encuadernadoras.

El conocimiento que tenemos sobre esta materia, sólo nos confirma que la encuadernación es sumamente importante en los estudios relacionados con bibliotecas e impresores. De ahí que su relevancia como elemento bibliográfico haya sido establecida por los bibliógrafos materiales como Gaskell, Bowers, y Tanselle, ${ }^{14}$ entre otros.

Sin embargo, sabemos que el mundo del impreso antiguo apenas ha comenzado su desarrollo como tema de conocimiento en nuestro país, lo que no justifica de ninguna manera que se descuide el desarrollo de una materia que encontramos en las publicaciones especializadas de otros países. Lo anterior afecta tanto a la formación como a la investigación relacionadas con disciplinas como la conservación, la restauración, la historia, el arte o la bibliotecología, que tienen por objeto el estudio del impreso antiguo como objeto material, cultural y social. Así, corremos el terrible riesgo de perder irremediablemente aquellos objetos materiales que denominamos impresos antiguos cuyo valor cultural es incalculable.

Ciertamente el conocimiento al que nos referimos no puede soportarse sin considerar las problemáticas de la formación y la investigación que caracterizan al mundo del impreso antiguo en nuestro país, el cual, podemos decir, sin temor a equivocarnos, se encuentra completamente aislado entre las disciplinas afines. Pero esta situación podría modificarse si desarrollamos investigación multidisciplinaria y trabajamos directamente con los materiales custodiados. Sin embargo dicha modificación exige que previamente se le otorgue un valor a la encuadernación histórica para que ésta sea respetada en 
el contexto de la colección bibliográfica, pero también implicaría reconocer que:

[...] la investigación inductiva, experimental y descriptiva no es meramente subsidiaria de la deductiva intelectual, y que compete al historiador del libro, pues, aun en los casos en que la fuente histórica proporciona algún dato sobre la actividad encuadernadora de un taller o sobre la existencia de una colección concreta, siempre enriquecerá los criterios mencionados con observaciones concretas de $<$ primera mano $>$ del material librario e interesa directamente, y enriquece, el trabajo descriptivo del catalogador en un campo tan necesitado de estudios como descuidado por los propios bibliotecarios. Las contadas y sucintas referencias a la descripción de encuadernaciones que encontramos tanto en los inventarios de libros que nos han llegado [...] como en los modernos catálogos al uso sobre fondo antiguo, prueban dicha circunstancia. ${ }^{15}$

El estado en que se encuentra la investigación en México en relación con la encuadernación histórica del impreso antiguo permite identificar dos tendencias que no favorecen la construcción de su valor cultural. La primera se refiere al escaso valor que la academia le da a la elaboración de catálogos y bibliografías como instrumentos para la investigación especializada. No es un secreto que una buena investigación histórica identifica previa y puntualmente sus fuentes. La segunda tendencia es la escasa investigación que se realiza sobre este tema, lo cual permite que se hagan afirmaciones sobre la época de la encuadernación que no siempre son ciertas en tanto que no se soportan sobre datos concretos y verificables.

Reconocer nuestras limitaciones en la investigación especializada, y también nuestros aciertos (aunque escasos), contribuiría a reforzar nuestra valoración cultural en general. Y de ese modo la garantía de socializar el bien patrimonial no resultaría una tarea imposible sino deseable, y consolidaría el marco de la cooperación y el intercambio no solamente entre instituciones sino entre profesionistas de diversas disciplinas preocupados por la destrucción y el deterioro que hoy nos caracteriza, pero también nos horroriza. Quizá en un futuro no muy lejano podamos realizar investigaciones multidisciplinarias con el mismo objetivo: la recuperación y transmisión del libro antiguo como herencia cultural. Pero este anhelo requiere necesariamente que primero se produzca la introducción de materias relevantes en los programas de formación relacionados con el patrimonio documental: bibliografía material, conservación, paleografía, latín, tratamiento digital, entre otras, que le indiquen 
a las instituciones de custodia que no están solas en su responsabilidad social y cultural con los bienes patrimoniales. Todo esfuerzo encaminado al rescate y la recuperación del libro antiguo y de los documentos que lo constituyen será, sin duda, agradecido por las futuras generaciones que no se verán privadas de este trozo de su patrimonio y cuya recuperación nos ayudará a entender mejor la historia del libro en México.

\section{CONCLusiones}

Desde nuestra perspectiva es indudable que la encuadernación del impreso antiguo constituye un recurso cultural en permanente riesgo si se mantiene la valoración que sobre la misma encontramos en el panorama cultural mexicano. Consideramos que si identificamos las características materiales de la encuadernación y diseñamos categorías para favorecer su valoración, estaremos contribuyendo a la comprensión del libro, como un objeto material que debe ser conservado con todos sus elementos internos y externos, para asegurar la transmisión completa de su significado y representación cultural.

Por eso nos sumamos a la valoración de la encuadernación como constituyente inseparable del libro, un elemento que posee valores propios tanto o más preciados que los del libro que protegen, y consideramos que es nuestra responsabilidad garantizar su permanencia y transmisión a las generaciones futuras.

Si reconocemos que la misma ausencia de investigación especializada incrementa la problemática relacionada con la conservación del impreso antiguo, estaremos en condición de entender al bien cultural como un objeto integral, no como un conjunto de elementos que pueden separarse y concebirse como unidades aisladas. De esta manera los conservadores y restauradores de encuadernaciones en México comprenderían este valor y podrían documentar la mayor parte de sus intervenciones.

Una comprensión de esta naturaleza impediría que muchas intervenciones en impresos antiguos se realizaran sin hacer antes una valoración y reflexión teórica que sustentara los procedimientos empleados. De ese modo dejaríamos en el pasado aquellas intervenciones que se han limitado a reparar los materiales deteriorados -sin registro o reflexión previa-, o a sustituir los materiales "viejos y deteriorados" por nuevas encuadernaciones. ${ }^{16}$ No lamentaríamos que un gran número de impresos antiguos se encuentren actualmente presentados por "radiantes" cubiertas de piel y keratol -que nada

16 Este fue el panorama predominante en la conservación de libros en México, lo que no significa que no existieran ejemplos aislados de restauradores preocupados por realizar intervenciones de restauración respetuosas de la integridad del libro. 
tienen que ver con el contenido original resguardado-. Afortunadamente dicha situación se encuentra en un proceso de modificación paulatino, pues se está generando un cuerpo de profesionistas e investigadores de distintas áreas, interesados en salvaguardar al libro como un objeto integral; es decir, compuesto por elementos textuales e históricos en una sola unidad. Sin embargo este tipo de intereses carece de información fiable sobre los tipos de encuadernaciones conservados en nuestras bibliotecas. Sin lugar a dudas este elemento histórico ha sido uno de los aspectos de valoración cultural más abandonados tanto por los bibliotecarios como por los conservadores.

Pero el cambio gradual de la valoración del impreso antiguo nos permite apuntalar que las anotaciones o las manchas que ese objeto presenta, no son meros agregados o "agentes de deterioro", sino los vestigios o huellas que determinadas acciones dejaron en el objeto.

La salvaguarda del patrimonio bibliográfico -manoseado constantemente y poco comprendido por políticos y funcionarios- integra estas dos grandes esferas de apreciación: el impreso antiguo en su contenido y los elementos históricos que lo complementan. Sin esta valoración, el mero almacenamiento de los materiales bibliográficos no cumple con el compromiso patrimonial y, a la larga, redunda en el olvido y destrucción de las colecciones.

De ahí que nos atrevamos a proponer el desarrollo de modelos constructivos sobre las encuadernaciones mexicanas, que incluya la caracterización de los materiales utilizados en su construcción. Pero esta tarea debe ser el resultado de un trabajo interdisciplinario entre bibliotecarios, archivistas, historiadores, historiadores del arte, libreros y conservadores, entre otros.

Además los resultados de esta colaboración profesional no deberán quedar en el marco cerrado de las instituciones culturales de custodia. Por el contrario, este trabajo deberá favorecer y fortalecer el desarrollo de exposiciones, tanto presenciales como virtuales, que conduzcan al reconocimiento del valor cultural y por tanto patrimonial de las encuadernaciones. Es ésta una tarea que deben abordar las bibliotecas y archivos mexicanos como parte de sus actividades cotidianas, soportadas conjuntamente en el desarrollo del conocimiento sobre la materia. Esta situación ideal debe incluir a todas las instituciones, nacionales, estatales, privadas, etcétera, que custodian encuadernaciones valiosas.

De esta manera se evitaría la pérdida patrimonial lenta y gradual de nuestras colecciones, que no nos permite ahondar en investigaciones tendientes a esclarecer la procedencia de las colecciones de los impresos antiguos conservados. El estudio de la encuadernación original podría ayudar a identificar lo que aún queda de las magníficas bibliotecas que dieron origen a nuestro patrimonio librario. La plena identificación de la procedencia de los impresos antiguos 
es un punto pendiente y en éste la encuadernación tiene su propio lugar y mérito cultural.

Ojalá que la construcción de nuestra modernidad no olvide el resguardo de nuestra memoria bibliográfica con todas las facetas que la caracterizan, y que sea el inicio de la construcción de un terreno social derivado de la investigación y no el mantenimiento de feudos disciplinares.

\section{BiBLIOgRAFÍA}

Abad, Julián Martín, "Incunables, post-incunables y libros antiguos", en Exposición virtual Civitas Librorum (La ciudad de los libros), Centro Virtual Cisneros, Universidad de Alcalá. Texto disponible en http://www.centrocisneros.uah.es/civitas/texto4.htm [Consultado: marzo de 2005] , "La valoración del libro: el punto de vista del bibliotecario de fondo antiguo", en Ciclo de Conferencias sobre Bibliofilia y Mercado del Libro, Biblioteca Histórica Marques de Valdecilla. Texto disponible en http://www.ucm.es/BUCM/foa/conferencia2.pdf [Consultado: noviembre de 2004]

Brugalla, Emilio, Tres ensayos sobre el arte de la encuadernación, Madrid: Ollero \& Ramos, 2000. , En torno a la encuadernación y las artes del libro: diez temas académicos, Madrid: CLAN, 1996.

Carpallo Bautista, Antonio, Análisis documental de la encuadernación española, Madrid: Asociación para el fomento de la encuadernación de arte, 2002.

, "El papel de la conservación documental como disciplina al servicios de los profesionales de la documentación”, Texto disponible: http://www.ucm.es/info/multidoc/multidoc/revista/num10/paginas/pdfs/acarpallo.pdf [Consultado: noviembre de 2004]

Checa Cremades, José Luis, La encuadernación renacentista en la Biblioteca del Monasterio de El Escorial: Introducción al estudio de la decoración exterior del libro en la España de Felipe II, Madrid: Ollero \& Ramos, 1998. , El libro antiguo, Madrid: Acento Editorial, 1999.

Cloonan, Michèle Valerie, "Bookbinding, aesthetics, and conservation”, en Libraries \& Culture, Vol. 30, no. 2 (spring 1995). P. 137-152. , Early Binding in Papers: a Brief History of European Hand-made Paper Covered Books with a Multilingual Glossary, Great Britain: G.K. HALL, 1991.

Cockerell, Douglas, Bookbinding and the Care of Books, Nueva York: Lyons and Burford, 1991

Enciclopedia de la encuadernación, Madrid: Ollero \& Ramos, 1998. 
Foot, Mirjam, "The future of bookbinding research", en The Book en Compassed: Studies in Twentieth-century Bibliography / ed. Peter Davison, Cambridge: Cambridge University Press, 1992. p. 99-106 The History of Bookbinding as a Mirror of Society, Londres: The British Library, 1986.

For the Love of the Binding: Studies in Bookbinding History Presented to Mirjam Foot/edited by David Pearson. Londres: The British Library: Oak Knoll Press, 2000.

García, Idalia, "El legado bibliográfico en México: un aspecto inconcluso de la investigación bibliotecológica", en Memoria del XXI Coloquio de Investigación Bibliotecológica y de la Información: la investigación bibliotecológica en la era de la información, México: UNAM. CUIB, 2004. p. 226-247.

Gómez Raggio, Francisco, El libro de la encuadernación, $1^{\circ}$ reimp. Madrid: Alianza Editorial, 1996.

Lafaye, Jacques, Albores de la imprenta: el libro en España y Portugal y sus posesiones de ultramar, siglos XV y XVI, México: FCE, 2002

Marks, P. J. M., The British Library Guide to Bookbinding: History and Techniques, Milan: The British Library, 1998.

Martín, Henri-Jean, Historia y poder de lo escrito, Gijón: Trea, 1999

Martin Dudin, René, Arte del encuadernador y dorador de libros, Madrid: Ollero \& Ramos, 1997.

Monje Ayala, Mariano, El arte de la encuadernación, Madrid: CLAN, 1995.

Pedraza Gracia, Manuel J., "Concepto, estructura material y formal y descripción del libro antiguo”, p. 11-48, en Tasación, valoración y comercio del libro antiguo (Textos y materiales), Zaragoza: Universidad de Zaragoza, 2002.

Raros y preciosos: encuadernación de arte actual en las bibliotecas europeas, Madrid: Fundación Central Hispano: Asociación para el Fomento de la Encuadernación de Arte, 1997.

Romero de Terreros, Manuel, Encuadernaciones artísticas mexicanas, Siglo XVI al XIX, México: Secretaria de Relaciones Exteriores, 1932.

Sánchez Bueno de Bonfil, María Cristina, El papel del papel en la Nueva España, México: INAH, 1993

Sarriá Rueda, Amalia, "De libros raros y antiguos", en La estética del libro español: manuscritos e impresos españoles hasta finales del siglo XVI en la Biblioteca Lázaro Galdiano / José Antonio Yeves Andrés, Madrid: Fundación Lázaro Galdiano, 1997. p. 71-85.

Tanselle, G. Thomas. "The Bibliographical Description of Patterns", Studies in Bibliography, Volume 23 (1970), Texto disponible en http://etext.lib.virgdu/bsuva/sb/ [Consultado: marzo de 2005]

Yeves, Juan Antonio. "Don José Lázaro: el bibliófilo y su biblioteca", p. 9-49, en La estética del libro español: manuscritos e impresos españoles hasta finales del siglo XVI en la Biblioteca Lázaro Galdiano, Madrid: Fundación Lázaro Galdiano, 1997. 